Article

\title{
Emergency FMD Serotype O Vaccines Protect Cattle against Heterologous Challenge with a Variant Foot-and-Mouth Disease Virus from the O/ME-SA/Ind2001 Lineage
}

\author{
Nagendrakumar Balasubramanian Singanallur ${ }^{1, * \mathbb{D}}$, Aldo Dekker ${ }^{2} \mathbb{D}$, Phaedra Lydia Eblé ${ }^{2}$, Froukje van \\ Hemert-Kluitenberg ${ }^{2}$, Klaas Weerdmeester ${ }^{2}$, Jacquelyn J Horsington ${ }^{1}$ and Wilna Vosloo ${ }^{1}$ \\ 1 Australian Centre for Disease Preparedness, CSIRO-Health \& Biosecurity, 5 Portarlington Road, \\ Geelong, VIC 3220, Australia; jacquelynjh@gmail.com (J.J.H.); wilna.vosloo@csiro.au (W.V.) \\ 2 Laboratory Vesicular Diseases, Department of Virology and Molecular Biology, Wageningen Bioveterinary \\ Research, Houtribweg 39, 8221 RA Lelystad, The Netherlands; Aldo.Dekker@wur.nl (A.D.); \\ phaedra.eble@wur.nl (P.L.E.); W.Hemert@upcmail.nl (F.v.H.-K.); KWeerd@hotmail.com (K.W.) \\ * Correspondence: nagendra.singanallur@csiro.au; Tel.: +61-3-5227-5020
}

\section{check for} updates

Citation: Singanallur, N.B.; Dekker, A.; Eblé, P.L.; van Hemert-Kluitenberg, F.; Weerdmeester, K.; Horsington, J.J.; Vosloo, W. Emergency FMD Serotype O Vaccines Protect Cattle against Heterologous Challenge with a Variant Foot-and-Mouth Disease Virus from the O/ME-SA/Ind2001 Lineage. Vaccines 2021, 9, 1110. https:// doi.org/10.3390/vaccines9101110

Academic Editor: Elizabeth Rieder

Received: 21 August 2021

Accepted: 21 September 2021

Published: 29 September 2021

Publisher's Note: MDPI stays neutral with regard to jurisdictional claims in published maps and institutional affiliations.

Copyright: (c) 2021 by the authors. Licensee MDPI, Basel, Switzerland. This article is an open access article distributed under the terms and conditions of the Creative Commons Attribution (CC BY) license (https:/ / creativecommons.org/licenses/by/ $4.0 /)$.
Abstract: Vaccination is one of the best approaches to control and eradicate foot-and-mouth disease (FMD). To achieve this goal, vaccines with inactivated FMD virus antigen in suitable adjuvants are being used in addition to other control measures. However, only a limited number of vaccine strains are commercially available, which often have a restricted spectrum of activity against the different FMD virus strains in circulation. As a result, when new strains emerge, it is important to measure the efficacy of the current vaccine strains against these new variants. This is important for countries where FMD is endemic but also for countries that hold an FMD vaccine bank, to ensure they are prepared for emergency vaccination. The emergence and spread of the O/ME-SA/Ind-2001 lineage of viruses posed a serious threat to countries with OIE-endorsed FMD control plans who had not reported FMD for many years. In vitro vaccine-matching results showed a poor match $\left(\mathrm{r}_{1}\right.$-value $\left.<0.3\right)$ with the more widely used vaccine strain $\mathrm{O}_{1}$ Manisa and less protection in a challenge test. This paper describes the use of the $\mathrm{O} 3039$ vaccine strain as an alternative, either alone or in combination with the $\mathrm{O}_{1}$ Manisa vaccine strain with virulent challenge by a O/ME-SA/Ind-2001d sub-lineage virus from Algeria (O/ALG/3/2014). The experiment included challenge at 7 days post-vaccination (to study protection and emergency use) and 21 days post-vaccination (as in standard potency studies). The results indicated that the $\mathrm{O} 3039$ vaccine strain alone, as well as the combination with $\mathrm{O}_{1} \mathrm{Manisa}_{\text {, }}$ is effective against this strain of the O/ME-SA/Ind/2001d lineage, offering protection from clinical disease even after 7 days post-vaccination with a reduction in viraemia and virus excretion.

Keywords: foot-and-mouth disease virus; vaccine efficacy; serotype O/ME-SA/Ind2001 variant; heterologous challenge; cattle

\section{Introduction}

Foot-and-mouth disease (FMD) is a contagious infectious disease of cloven-hoofed animals. The disease presents as lesions on areas of friction such as the mouth, feet, and teats in lactating animals, but sub-clinical infections can also occur, especially in sheep and goats. The disease is caused by the FMD virus (FMDV), belonging to the Aphthovirus genus of the family Picornaviridae. Seven serotypes of FMDV (A, O, C, Asia 1, and South African Territories 1, 2, and 3) have been identified, and multiple genotypes/topotypes and lineages occur within each serotype $[1,2]$.

FMD is widely prevalent, with the disease circulating in regions estimated to contain $77 \%$ of the global livestock population, affecting a large proportion of animals during outbreaks, often involving multiple species at the same time. These factors collectively lead to a huge disease burden and have a significant global animal health and socio-economic 
impact [3]. The disease can potentially have serious economic and social implications if infection occurs in countries that are FMD-free and are major producers and exporters of livestock and livestock products. For example, most of the economic costs of a hypothetical FMD outbreak in Australia arise from revenue losses caused by immediate and prolonged import bans by Australia's main trading partners, which are estimated to be in excess of $\$ 50$ billion over 10 years [4]. Maintenance of the World Organisation for Animal Health (OIE) FMDV-free status is critical for the free trade of animals and animal products.

One of the main approaches to FMD control and eradication in endemic countries is through vaccination with inactivated FMDV antigen formulations with suitable adjuvants [5]. Vaccination was successfully used to control the disease in several formerly endemic countries in Europe and most countries in South America [6]. In addition, the unprecedented magnitude of slaughter to eradicate FMDV in the UK underlined the need for alternative policies to 'stamping out' in FMD-free countries where vaccination is not routinely used [7]. Since this incursion into the European Union, most countries free from FMD will now consider emergency vaccination, based on their own risk assessment, should an outbreak occur [8].

During 2013, a new sub-lineage of serotype O FMDV, O/ME-SA/Ind2001, previously restricted to South Asia, emerged and spread within the Middle East and North Africa [9]. Different variants of the same virus were identified in the Middle East in the past, causing sporadic outbreaks in Kuwait (1997), Oman (2001) and UAE (2008) [10]. Algeria, Tunisia, and Morocco in North Africa, which had OIE-endorsed FMD control plans and had not reported FMD for many years, witnessed widespread outbreaks due to the O/MESA/Ind2001d lineage during 2014 [11]. Similar viruses were also reported from South East Asian nations: Lao PDR, Myanmar and Vietnam (2015) and Thailand (2016) [10,12]. Several sub-lineages (a-e) have appeared to date, with the recent emerging sub-lineage e moving into Pakistan [13,14]. The antigen-matching studies carried out by the World Reference Laboratory (WRL) for FMD showed that these isolates had a poor antigenic match with the $\mathrm{O}_{1}$ Manisa vaccine strain, but a moderate to good match with the O3039 vaccine strain [9].

A previous study in cattle using a high-potency $\mathrm{O}_{1}$ Manisa vaccine (estimated 17 $\mathrm{PD}_{50} /$ dose) and challenge with an O/ME-SA/Ind2001d lineage virus isolated from Algeria $(\mathrm{O} / \mathrm{ALG} / 3 / 2014)$ resulted in a heterologous $\mathrm{PD}_{50}$ value of approximately 3.5 [11]. The challenge virus (O/ALG/3/2014) belongs to the O/ME-SA/Ind2001d lineage and is heterologous to both the $\mathrm{O}_{1}$ Manisa and $\mathrm{O} 3039$ vaccine strains with relative homology $\mathrm{r}_{1}$-value $<0.3$ by virus neutralisation test [9]. The study concluded that the high-potency $\mathrm{O}_{1}$ Manisa vaccine would be effective against the O/ME-SA/Ind2001 lineage of viruses, but further studies to evaluate other vaccine candidates or multivalent combinations should be carried out for potential emergency purposes in FMD-free settings [11]. The emergence of O/ME-SA/Ind2001 lineage and subsequent spread into South East Asia poses a risk to the Australian livestock industry and to other FMD-free countries in the region. Its spread westward has caused severe economic losses and increased the disease burden in Northern Africa and Middle East Asia. Therefore, the aim of the present study was to test the efficacy of an $\mathrm{O} 3039$ vaccine alone and in combination with $\mathrm{O}_{1}$ Manisa (both formulated as emergency vaccine) in cattle at different timepoints post-vaccination when challenged with an O/ME-SA/Ind2001 lineage virus, and make recommendations on the vaccine strains to be included in vaccine banks.

\section{Materials and Methods}

\subsection{Experimental Animals}

The vaccine efficacy study was performed in the animal facility of Wageningen Bioveterinary Research (WBVR), Lelystad, The Netherlands, according to protocols for experimentation with live cattle approved by the Animal Ethics Committee of the Australian Animal Health Laboratory (AEC 1754) and the Dutch Animal Ethics Law (2016003/LVZ194). In total, 23 Holstein Friesian or Holstein Friesian cross-bred cattle (aged 8-12 months and weighing approximately $200-250 \mathrm{~kg}$ ) were used for the study. The cattle were housed in 
a tie-stall to limit the transmission of virus between the cattle and ensure independent observations per cow.

\subsection{Viruses and Vaccines}

FMDV O/ALG/3/2014 (O-ALG) cattle passaged challenge virus was obtained from the Pirbright Institute [11], titrated on primary lamb kidney cells and was found to have a titre of $7.95 \log _{10}$ plaque-forming units (PFU)/mL. The virus was originally isolated by the Istituto Zooprofilattico Sperimentale della Lombardia dell'Emilia Romagna, Italy, from an outbreak in Algerian cattle during 2014, and subsequently passaged in cattle to prepare the cattle challenge virus, and in cell culture for in vitro assays. The challenge virus was diluted in Minimum Essential Medium with Hanks' balanced salts, $2 \%$ foetal bovine serum (FBS) and antibiotics (final concentration $20 \mathrm{IU} / \mathrm{mL}$ penicillin, $20 \mathrm{mg} / \mathrm{mL}$ streptomycin, $0.4 \mathrm{mg} / \mathrm{mL}$ amphotericin $\mathrm{B}, 10 \mathrm{mg} / \mathrm{mL}$ polymyxin $\mathrm{B}$ and $48 \mathrm{mg} / \mathrm{mL}$ kanamycin sulphate) to give a final titre of $5.7 \log _{10} \mathrm{PFU} / \mathrm{mL}$. O3039 and $\mathrm{O}_{1}$ Manisa viruses for virus neutralisation test (VNT) were supplied by WBVR, Lelystad. High-potency double oil emulsion (DOE) vaccines, formulated with proprietary adjuvants, with a combination of vaccine strains $\mathrm{O} 3039$ and $\mathrm{O}_{1}$ Manisa (Combo; both strains at $>6 \mathrm{PD}_{50} /$ dose) or O3039 alone ( $>6 \mathrm{PD}_{50} /$ dose), were prepared from the antigen reserve of the Australian FMD vaccine bank by Merial Company Limited, United Kingdom, and $2 \mathrm{~mL}$ was administered intramuscularly in the side of the neck, according to the manufacturer's recommendations.

\subsection{Immunisation, Challenge, Clinical Score and Sample Collection}

Four groups of 5 cattle were vaccinated with either the bivalent Combo or a monovalent O3039 vaccine and challenged at 21 days post-vaccination (dpv, Combo-21 or O3039-21) or $7 \mathrm{dpv}$ (Combo-7 or O3039-7). The vaccinated cattle and three unvaccinated control cattle (UVC) were challenged with $0.2 \mathrm{~mL}$ of $10^{5.7} \mathrm{PFU} / \mathrm{mL}$ FMDV O/ALG by intra-dermal inoculation (IDL) into two locations of the tongue, with $0.1 \mathrm{~mL}$ per location. For this study, only lesions on the feet were considered generalisation of disease and, therefore, not protected [15]. Mouth and nose lesions at sites other than the injection sites (dental pad, lips, etc.) were recorded but were not considered unprotected. Rectal temperatures were recorded daily, and animals were examined under anaesthesia for clinical lesions on 4 and 8 days post-challenge ( $\mathrm{dpc}$ ). Pain relief was pre-emptively given $0-4$ days after challenge, and then at the onset of moderate clinical signs using Flunixin meglumine @3.33 mg/Kg body weight, equivalent to $1 \mathrm{~mL} / 15 \mathrm{Kg}$ body weight (Finadyne pour-on $50 \mathrm{mg} / \mathrm{mL}$, MSD Animal Health, the Netherlands). The number of animals showing disease generalisation post challenge based on foot lesions were counted for each group and used to calculate the difference in protection between different groups. Clotted blood from Combo-21 or O3039-21 groups were sampled on $-21,-18,-14,-10,-7,-4,0,1-7,11,14,18,21,25,28$ and $32 \mathrm{dpc}$ and the animals, while Combo-7 or O3039-7 groups were sampled on $-7,-4$, $0,1-7,11,14,18,21,25,28$ and $32 \mathrm{dpc}$. The unvaccinated control animals were sampled on $0,1-7,11,14,18,21,25,28$ and $32 \mathrm{dpc}$. The sera were collected after centrifugation and stored at $-80^{\circ}$ until testing. The oral fluid was collected on $0,1-7,11,14,18,21,25$, 28 and $32 \mathrm{dpc}$ with Salivette swabs, extracted using $0.5 \mathrm{~mL}$ of minimal essential medium supplemented with $5 \%$ fetal bovine serum and 10\% antibiotic cocktail and transferred to fresh tubes. Nasal swabs were collected on the same days as the oral swabs using sterile cotton swabs and placed in $2 \mathrm{~mL}$ of minimal essential medium supplemented with $5 \%$ fetal bovine serum and 10\% antibiotic cocktail [16-20]. Oro-pharyngeal fluids were collected using probang cups on 0,11,14,18,21, 25, 28 and 32 dpc and diluted 1:1 in Earle's MEM ( $2 \%$ fetal bovine serum and $2 \%$ antibiotic cocktail [21]. All samples were stored at $-80^{\circ}$ until testing.

\subsection{Serological Assays to Measure Antibodies}

Serum samples were examined for FMDV neutralising antibodies using VNT, performed using IBRS-2 cells following standard procedures [15,22]. The VNT was performed 
to assess the neutralising antibody titre against the homologous vaccine strains O3039 and $\mathrm{O}_{1}$ Manisa, and the heterologous challenge virus O-ALG. The neutralising antibody titres were calculated as the $\log _{10}$ of the reciprocal of the final antibody dilution required for $50 \%$ neutralisation of $100 \mathrm{TCID}_{50}$ of virus. Animals that showed a titre of $\log _{10}>1.20$ were considered positives [15]. Antibodies to the non-structural proteins (NSP) of FMDV were detected using the PrioCHECK ${ }^{\circledR}$ FMDV-NS kit (Thermo Fisher, Waltham, MA, USA) and sera showing a percentage inhibition value (PI) of $\geq 50$ were considered positives, according to the manufacturer's instructions.

\subsection{Viraemia and Virus Excretion}

Viraemia (serum) and virus excretion in oral and nasal swabs and probang samples were studied by virus titration and real-time RT-PCR. Primary ovine kidney cells supplied by the WBVR were used to perform virus isolation and titration using a standard plaque assay, and the results expressed as $\log _{10} \mathrm{PFU} / \mathrm{mL}$ [23]. Samples were recorded as negative when no plaques were observed. As the plates were washed and stained, a second passage was not possible. Total RNA from $200 \mu \mathrm{L}$ of serum, oral and nasal secretions (as mentioned above) and probang samples were isolated using the MagNA Pure 96 DNA and Viral NA Large Volume kit on the MagNA Pure 96 system (Roche ${ }^{\circledR}$ Life Science) and real-time RTPCR was carried out using the LightCycler RNA Amplification Kit Hybridisation Probes and LightCycler 480 (Roche ${ }^{\circledR}$ Life Science) using the protocol described by Moonen et al. 2003 [24]. Samples were declared positive when the fluorescence signal rose above the background signal (crossing point determined automatically by the second derivative maximum method for quantification by the software supplied by Roche ${ }^{\circledR}$ ).

\subsection{Statistical Analysis}

Clinical protection based on count data were analysed using the two-sided Fischer exact test. Group means and standard deviations were calculated and expressed as Mean \pm SD. Longitudinal data for continuous outcomes in multiple vaccine groups were analysed using a linear mixed-effects model (lme library) [25]. ANOVA was used to test the statistical differences between groups. If a statistical difference was found, a pairwise $t$-test (with Holm correction) was used to analyse differences between groups. Longitudinal data (virus isolation, RT-PCR results and NSP response) were analysed using the animal number as random variable and dpc, group and vaccination (yes or no) as possible explanatory variables. Using forward selection, the best model, with the lowest Akaike's Information Criterion (AIC), was chosen. For the NSP responses, the data from 0 to $35 \mathrm{dpc}$ were analysed, with the percent-inhibition value (PI) used as a response variable. Cattle number was added as a random variable. Dpc (as a factor) and vaccine group were analysed as explanatory variables, as well as interactions. Data on virus isolation and RT-PCR were also analysed the same way. In all models, explanatory variables were selected based on the lowest AIC using forward selection. A statistical analysis was performed using R version 4.0.2 [26]. All results are presented in the Supplementary Word file.

\section{Results}

\subsection{Post Challenge Outcomes (Temperature and Clinical Disease)}

The clinical outcome of the vaccine efficacy studies is summarised in Supplementary Table S1. All cattle challenged at $21 \mathrm{dpv}$ (Combo-21 and O3039-21) had no lesions on their feet and were considered protected. The three UVC cattle, as well as one in the Combo-7 (\#9672) and two in the O3039-7 vaccinated groups (\#9674 and 9677), showed generalization, with lesions on one or more feet. The difference in clinical outcome between the four vaccine groups was not significant $(p=0.561$; Fisher's Exact Test, two-sided, Supplementary Text ST-1), but when compared with the unvaccinated control groups, there was a significant difference ( $p=0.01129$; Fisher's Exact Test, two-sided, Supplementary Text ST-2). The difference in rectal temperatures between the vaccine groups was statistically insignificant $(p>0.05)$ but was significant when compared with the control group $(p=0.045)$. However, 
there was a significant difference in rectal temp between $0 \mathrm{dpc}$ and $1-4 \mathrm{dpc}$ in all groups $(1-3 \mathrm{dpc}-p<0.001$ and $4 \mathrm{dpc}-p=0.0076)$ ) (Figure 1; Supplementary Text ST-3).

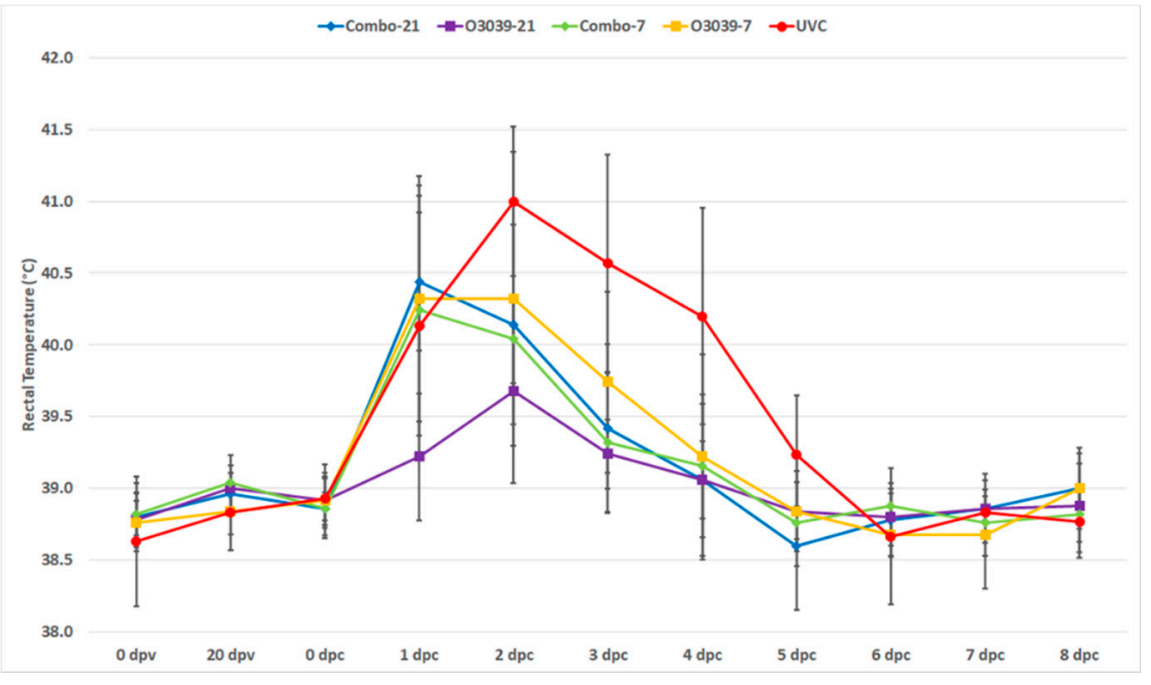

Figure 1. Mean rectal temperature $\left({ }^{\circ} \mathrm{C}\right)$ of cattle given a full dose of a $\mathrm{O} 3039+\mathrm{O}_{1}$ Manisa combination vaccine or $\mathrm{O} 3039$ monovalent vaccine and challenged on 21 or 7 days post vaccination, with O-ALG virus, with error bars representing standard error of the mean for each group. The broken line indicates temperature $\left(39.5^{\circ} \mathrm{C}\right)$ above which an animal is considered as having pyrexia; dpv-days post vaccination and $\mathrm{dpc}$-days post challenge.

\subsection{Serological Response to Vaccination at the Time of Challenge}

The sera from the four vaccinated and one unvaccinated control groups were all tested for neutralising antibodies using VNT against O3039, $\mathrm{O}_{1}$ Manisa and O-ALG. The control animals had no detectable neutralising antibodies to any of the three viruses on the day of challenge. All vaccinated animals developed antibody titres against their vaccine virus(es) but also against the other type $\mathrm{O}$ virus(es). In the vaccinated groups, higher titres were observed at $21 \mathrm{dpv}$ against all three viruses compared to $7 \mathrm{dpv}$ (Figure 2).

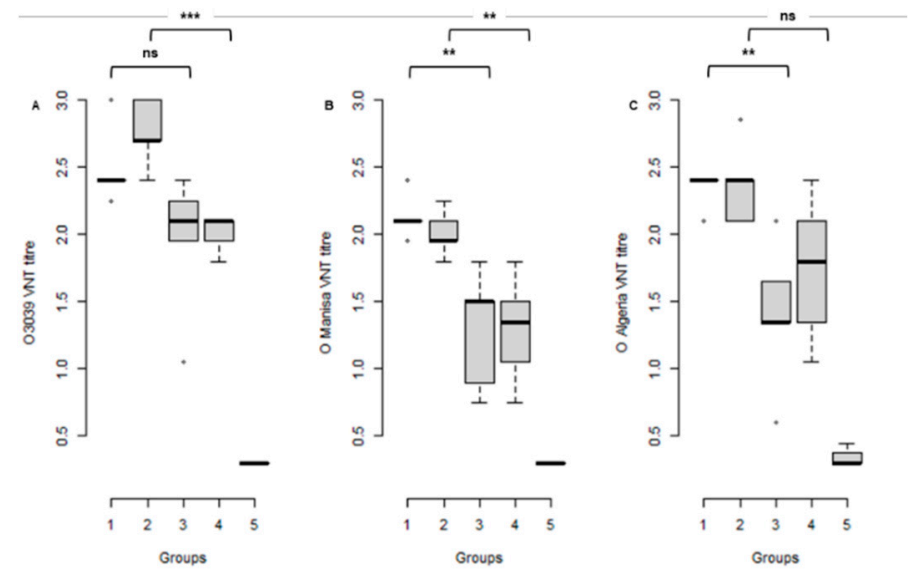

Figure 2. Box plot of serum antibody titres estimated by VNT of cattle vaccinated with $\mathrm{O} 3039+\mathrm{O}_{1}$ Manisa combination vaccine (Combo) or $\mathrm{O} 3039$ monovalent vaccine on the day of challenge (21 or 7 days post vaccination) with O Algeria 2014 (O-ALG). The horizontal line represents the median titre for each group. The serum antibody titres were estimated against $\mathrm{O} 3039$ (A), $\mathrm{O}_{1}$ Manisa (B) and O-ALG (C) viruses. Key: 1 = Combo-21, 2 = O3039-21, 3 = Combo-7, 4 = O3039-7, 5 = Unvaccinated Control. ns-No significant difference; ${ }^{* *}-p<0.01 ;{ }^{* *}-p<0.001$. The boxplots show the interquartile range (median represented as the thick horizontal line within the box, and the first and third quartile of the data) and the minimum and maximum values for each group connected to the boxes with the vertical line. 
Comparison of the neutralising antibodies at the time of challenge in a linear mixed model showed a significant difference between the virus used in the VNT as well as a significant difference for the interval between vaccination and challenge, but no differences between the neutralising antibody titres induced by the bivalent (Combo) and monovalent (O 3039) vaccine. The mean $\mathrm{O} 3039$ and $\mathrm{O}_{1}$ Manisa response differed significantly between the 21 and $7 \mathrm{dpv}$ groups ( $p=0.004$ and $p=0.0004$, respectively). However, the mean O-ALG response did not differ significantly between the 21 and $7 \mathrm{dpv}$ groups $(p>0.05)$ (Figure 2; Supplementary Text ST-4).

All animals responded to challenge with an increase in neutralising antibody and the differences in post-challenge response were not statistically significant (Supplementary file).

\subsection{NSP Antibody Responses}

Antibodies to the NSP of FMDV developed at a timepoint between 5 and $11 \mathrm{dpc}$ in all animals (sera were not collected daily). The linear mixed regression model analysis showed that dpc (as a factor), group and interaction between dpc and group best explained the NSP response (Supplementary File). The interaction shows that there was no significant difference $(p>0.05)$ between the vaccine groups, but a significant difference between day of challenge ( 21 or $7 \mathrm{dpv} ; p<0.05$ ) and post-challenge on 28 and $32 \mathrm{dpc}$ (Figure 3; Supplementary Text ST-5).

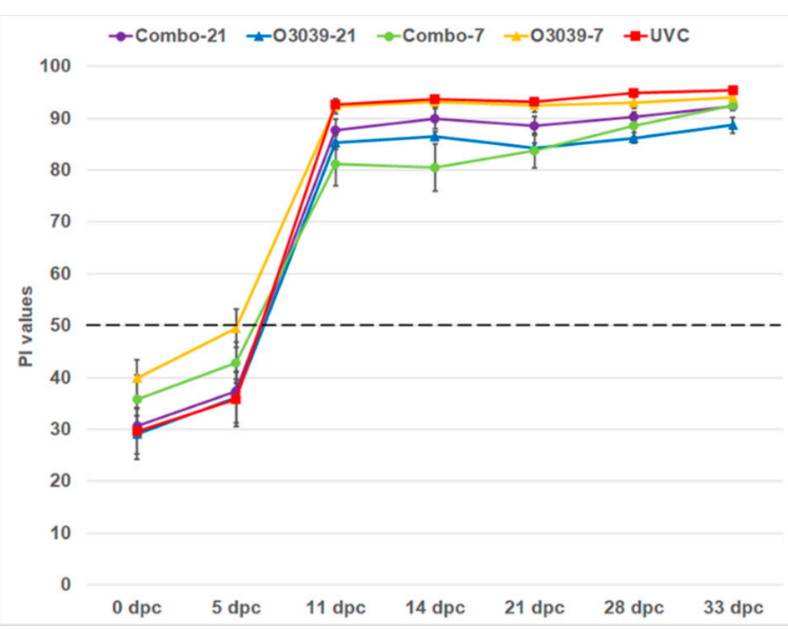

Figure 3. NSP antibody responses post-challenge in cattle given a $\mathrm{O} 3039+\mathrm{O}_{1}$ Manisa combination vaccine or $\mathrm{O} 3039$ monovalent vaccine and in unvaccinated cattle. dpc-day post-challenge; PI—mean per cent inhibition; horizontal dashed line indicates the cut-off level; Error bars represent standard error of mean PI values.

\subsection{Viraemia and Virus Excretion in Clinical Samples}

Infectious FMD virus and viral RNA were detected in the sera of all UVC cattle at 1-3 dpc. Except for one vaccinated animal, where viral RNA could be detected at $1 \mathrm{dpc}$ (O3039-7 group (\#9677)), no virus or RNA was detected in the sera of the cattle in the vaccine groups (Figure 4).

The oral swabs from all groups collected between 1 and $7 \mathrm{dpc}$ were positive for infectious virus and/or viral RNA due to the tongue lesions that occurred as a result of the IDL challenge and there was not a significant difference between the groups. Once the lesions were healed, virus was not detected in the oral swabs up to $32 \mathrm{dpc}$ (Figure 4).

Viral RNA and/or virus was intermittently detected in nasal secretions of all groups regardless of vaccination status between 1 and $7 \mathrm{dpc}$. The number of positive detections decreased over time, with only two positive RNA samples at $7 \mathrm{dpc}$ in vaccinated groups challenged $7 \mathrm{dpv}$. Significantly lower levels of infectious virus and/or viral RNA were detected in the nasal secretions of vaccinated animals when compared to the unvaccinated animals (one-way ANOVA $-p<0.001$ ) per day or over the total amount excreted during the 
viraemic and clinical phase of the disease (1-7 dpc). The viral RNA levels in the Combo-21 and O3039-21 cattle differed significantly from the Combo-7 and O3039-7 cattle (one-way ANOVA $-p<0.05$ ). (Figure 4).

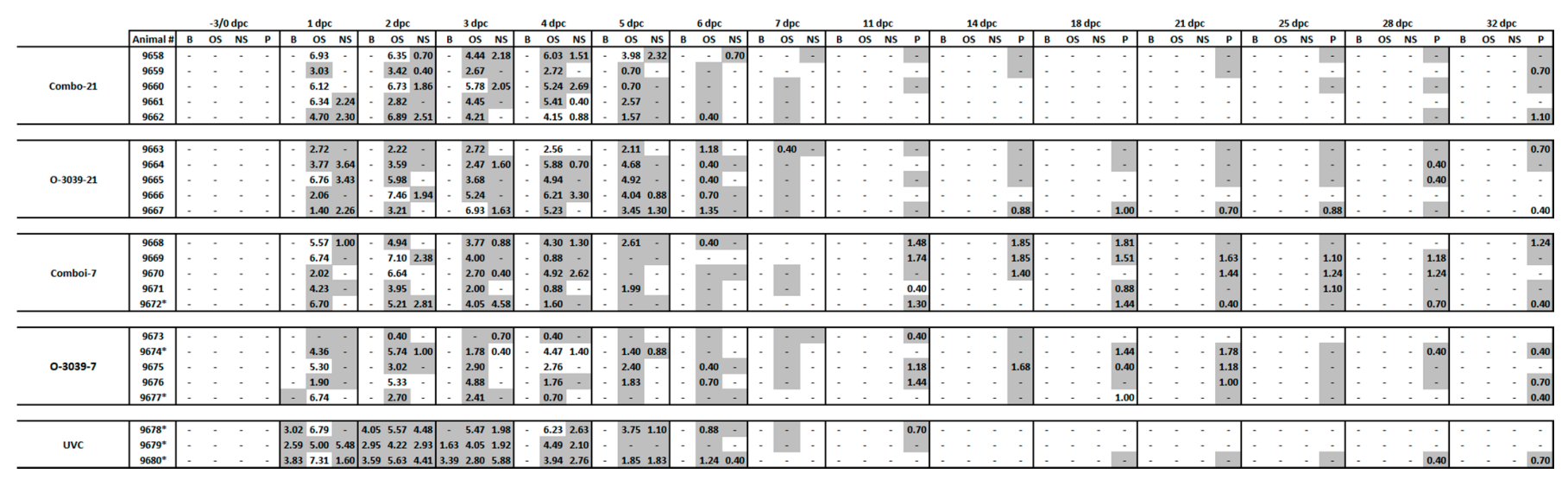

Figure 4. Virus isolation ( $\log _{10}$ PFU per $\mathrm{ml}$ ) and viral RNA detected in sera, swabs, and oro-pharyngeal fluids from 0 to 32 days post challenge. Animals were vaccinated with the $\mathrm{O} 3039+\mathrm{O}_{1}$ Manisa combination vaccine or O3039 monovalent vaccine and challenged 21 or 7 days post-vaccination with O-ALG virus. dpc-day post-challenge; B-Blood, OS-Oral Swab, NS-Nasal Swab, P-Oro-pharyngeal fluids collected using a probing cup, Cells with grey shade are positive for FMDV genome by PCR, numbers indicate the viral titres and "-" Indicates below the limit of detection by PCR or VI.

\subsection{Virus Persistence and Carrier Status}

Virus and viral RNA were detected in the probang samples of most vaccinated animals from $11 \mathrm{dpc}$ and there was no difference between the vaccinated and control groups. There was an increase in the number of positive animals in group Combo-21 up to $32 \mathrm{dpc}$ (Figure 4). The infectious virus titres were low and never exceeded $\log _{10} 2 \mathrm{PFU} / \mathrm{mL}$. The probang samples of only one of the unvaccinated control animals were positive between 18 and $32 \mathrm{dpc}$. These results indicated that 2-3 cattle in each of the vaccine groups and one in the UVC group developed virus persistence and could be considered carriers.

\section{Discussion}

The emergence of the novel O/ME-SA/Ind2001 lineage of FMD viruses continues to pose a major threat to the 'FMD free' countries in Europe and Northern Africa, and variants and several sublineages have emerged (a-e). An earlier study recommended the use of $\mathrm{O}_{1}$ Manisa vaccine strain for emergency use and control of outbreaks with $\mathrm{O} / \mathrm{ME}$ $\mathrm{SA} /$ Ind2001d sub-lineage and also suggested evaluation of other vaccine candidates (or multivalent combinations) that might potentially be used for emergency purposes in FMDfree setting [11]. The antigen-matching reports from the World Reference Laboratory in Pirbright indicated that an alternative vaccine strain, O3039, in the vaccine banks matched with the viruses of the above-mentioned lineage [9,27]. Keeping these results and recommendations in mind this study was designed to determine if the $\mathrm{O} 3039$ vaccine strain can provide better protection, either as a monovalent vaccine, or in combination with $\mathrm{O}_{1}$ Manisa. In addition, since these vaccines will be used during emergency responses in many countries, it was also necessary to determine how efficacious they will be soon after vaccination. In this study we compared the outcomes of virus challenge at 7 and $21 \mathrm{dpv}$. Both the $\mathrm{O} 3039$ monovalent vaccine and the combination vaccine with $\mathrm{O}_{1}$ Manisa (Combo) protected all cattle from clinical disease following challenge after $21 \mathrm{dpv}$ with O/ALG/3/2014 (O-ALG). Showing early protection at only 7 days between vaccination and challenge, both vaccines protected, on average, $70 \%$ of the cattle. This is despite the severe challenge model with high doses of virus injected directly into the tongue. Under field conditions, vaccinated cattle will be challenged by natural routes and direct contact with infected animals, which is seen as less severe. Protection at early timepoints 
post-vaccination has been made in several studies [28-30], indicating the usefulness of emergency vaccines that often contain more antigen per dose than routine vaccines.

The O3039 monovalent vaccine and Combo vaccines were very effective in reducing or preventing viraemia against the O/ME-SA/Ind2001d lineage as early as $7 \mathrm{dpv}$, as evidenced by real-time RT-PCR that showed viraemia in only one of the animals challenged $7 \mathrm{dpv}$, whilst no viraemia was detected in any of the other animals and groups. This contrasted with the unvaccinated animals, where infectious virus or viral RNA was detected for $3 \mathrm{dpc}$. Viraemia usually coincides with the clinical phase of FMD; therefore, decreasing this phase is an important aspect of disease control by limiting the clinical signs and lowering the extent of virus shedding [31].

We found no correlation between pyrexia and the development of clinical signs, which confirms the previous findings that pyrexia is not a reliable predictor of the development of clinical FMD signs $[11,30]$ and, therefore, not a practical indicator of FMDV infection. However, this could be a result of the administration of anti-pyrectics and analgesics (NSAIDs) for ethical considerations.

Virus/viral RNA was detected from the oral and nasal swabs between 1 and $7 \mathrm{dpc}$ in all the groups, indicating that these samples are valuable for identifying infection during an outbreak for surveillance activities. There was a marked reduction in virus shedding in the nasal secretions of the vaccinated animals compared to the unvaccinated animals, which will result in less virus in the environment and assist with disease control, confirming findings from previous studies that showed that vaccination can help prevent the spread of the virus within the infected premises and between farms [32].

One important aspect for disease control is the prevention of persistent infection, the co-called 'carrier state', defined as the presence of virus/viral RNA 28 days postinfection [33]. Although the probability of transmission from persistently infected livestock to other susceptible animals is low [34-36] or absent [37], when providing evidence of freedom from infection for reasons such as accessing trade markets or changing country disease status, it is also important to demonstrate the absence of persistently infected animals. This often has economic impacts due to increased surveillance costs when using vaccination and is one of the deterrents to using vaccination to control outbreaks in previously free countries or regions. Previous studies found that approximately $50 \%$ of unvaccinated infected animals show virus persistence, while vaccination decreases the number of persistently infected animals $[34,38]$ because the vaccinated animals did not show generalisation of the disease post-challenge. It was also shown that the number of persistently infected animals decreases over time [21]. In our study, viral RNA/virus was detected in most of the vaccinated animals, but at intermittent times and at very low titres $(<2 \mathrm{PFU} / \mathrm{mL})$ up to $32 \mathrm{dpc}$. Vaccination, therefore, did not prevent persistent infection at timepoints close to the challenge, but the level of live virus was low. However, despite this finding, disease models showed that there is no need to develop vaccines that provide sterile immunity $[34,35]$ and that current vaccines are suitable for control campaigns.

Antigen-matching studies by national and international reference laboratories give an indication of the match between new emerging isolates and the current vaccine strains. These studies are generally performed with reference sera raised using commercial vaccine formulations (payload equivalent to 3-6 $\mathrm{PD}_{50} /$ dose) and not emergency vaccine formulations (payload that provide $>6 \mathrm{PD}_{50} /$ dose). While $\mathrm{r}_{1}$-values provide valuable indications of vaccine efficacy when assessing homologous systems, the interpretation is less clear when the vaccine and virus are heterologous. In vivo challenge studies such as the one described here present valuable data on the efficacy of heterologous emergency vaccines.

\section{Conclusions}

The ever-evolving nature of FMDV poses a significant challenge to endemic and FMD-free countries that rely on vaccination to control the disease and incursions. Vaccine efficacy studies such as these provide additional evidence on whether a particular vaccine formulation will have a sufficient impact on clinical disease, virus excretion and 
persistent infection, even at early timepoints post-vaccination. These results are based on a small number of animals; therefore, it is prudent to expand such studies to more animals and other challenge viruses to confirm the efficacy of monovalent or combination vaccines. Given the epidemiological situation of FMD around the world and co-circulation of serotype $\mathrm{O}$ viruses belonging to different genotypes and lineages, we recommend that both $\mathrm{O}_{1}$ Manisa and $\mathrm{O} 3039$ are included in the vaccine banks.

Supplementary Materials: The following are available online at https://www.mdpi.com/article/10 .3390 /vaccines9101110/s1, Supplementary Table S1. Homologous and heterologous post vaccination neutralising antibody titres (21 or 7 days post vaccination) and clinical observations at 8 days post challenge in cattle vaccinated with a O-3039 + O1 Manisa combination vaccine (Combo) or O-3039 monovalent vaccine and an unvaccinated control group (UVC). Supplementary Text ST-1 vaccine groups against challenge Supplementary Text ST-2 vaccinated vs control against challenge Supplementary Text ST-3 body temperature Supplementary Text ST-4 Antibody titres and protective response Supplementary Text ST-5 NSP antibodies.

Author Contributions: Conceptualization, A.D. and W.V.; methodology, N.B.S., F.v.H.-K. and K.W.; formal analysis, N.B.S., J.J.H. and A.D.; data curation, N.B.S., P.L.E. and A.D.; writing-original draft preparation, N.B.S. and W.V.; writing-review and editing, N.B.S., J.J.H., W.V., P.L.E. and A.D.; project administration, W.V.; funding acquisition, W.V. and A.D. All authors have read and agreed to the published version of the manuscript.

Funding: This project is supported by Meat \& Livestock Australia (MLA; P.PSH.0779), through funding from the Australian Government Department of Agriculture, Water and the Environment as part of its Rural R\&D for Profit program (RRND4P-15-02-032), and by producer levies from Australian FMD-susceptible livestock (cattle, sheep, goats and pigs) industries and Charles Sturt University (CSU), leveraging significant in-kind support from the research partners. The research partners for this project are the Commonwealth Science and Industrial Research Organisation (CSIRO), CSU through the Graham Centre for Agricultural Innovation, the Bureau of Meteorology (BOM) and the Australian Department of Agriculture, Water and the Environment, supported by Animal Health Australia (AHA). The study was funded by the Ministry of Agriculture, Nature and Food Quality, the Netherlands (project WOT-01-003-011).

Institutional Review Board Statement: The study was performed in the animal facility of Wageningen Bioveterinary Research (WBVR), Lelystad, The Netherlands according to protocols for experimentation with live cattle approved by the Animal Ethics Committee of the Australian Animal Health Laboratory (AEC 1754) and the Dutch Animal Ethics Law (2016003/LVZ194).

Informed Consent Statement: Not applicable.

Data Availability Statement: All data are archived as per the CSIRO policies and guidelines.

Acknowledgments: The authors acknowledge the contribution of the animal ethics committee members for suggesting improvements in our study design and animal husbandry protocols. The authors acknowledge excellent support provided by the animal care team of WVBR, Lelystad during the animal studies.

Conflicts of Interest: The authors declare no conflict of interest.

\section{References}

1. Rodrigo, K.J.; Dopazo, J. Evolutionary Analysis of the Picornavirus Family. J. Mol. Evol. 1995, 40, 362-371. [CrossRef] [PubMed]

2. Domingo, E.; Escarmis, C.; Baranowski, E.; Ruiz-Jarabo, C.M.; Carrillo, E.; Nunez, J.I.; Sobrino, F. Evolution of Foot-and-Mouth Disease Virus. Virus Res. 2003, 91, 47-63. [CrossRef]

3. Knight-Jones, T.J.; Rushton, J. The Economic Impacts of Foot and Mouth Disease-What Are They, How Big Are They and Where Do They Occur? Prev. Vet. Med. 2013, 112, 161-173. [CrossRef] [PubMed]

4. Buetre, B.; Wicks, S.; Kruger, H.; Millist, N.; Yainshet, A.; Garner, G.; Duncan, A.; Abdalla, A.; Trestrail, C.; Hatt, M.; et al. Potential Socio-Economic Impacts of an Outbreak of Foot-and-Mouth Disease in Australia; Commonwealth of Australia: Canberra, Australia, 2013.

5. Brehm, K.E.; Kumar, N.; Thulke, H.H.; Haas, B. High Potency Vaccines Induce Protection against Heterologous Challenge with Foot-and-Mouth Disease Virus. Vaccine 2008, 26, 1681-1687. [CrossRef] 
6. Clavijo, A.; Sanchez-Vazquez, M.J.; Buzanovsky, L.P.; Martini, M.; Pompei, J.C.; Cosivi, O. Current Status and Future Prospects to Achieve Foot-and-Mouth Disease Eradication in South America. Transbound. Emerg. Dis. 2017, 64, 31-36. [CrossRef] [PubMed]

7. Geale, D.W.; Barnett, P.V.; Clarke, G.W.; Davis, J.; Kasari, T.R. A Review of Oie Country Status Recovery Using Vaccinate-to-Live Versus Vaccinate-to-Die Foot-and-Mouth Disease Response Policies II: Waiting Periods after Emergency Vaccination in FMD Free Countries. Transbound. Emerg. Dis. 2015, 62, 388-406. [CrossRef]

8. Garland, A.J.; de Clercq, K. Cattle, Sheep and Pigs Vaccinated against Foot and Mouth Disease: Does Trade in These Animals and Their Products Present a Risk of Transmitting the Disease? Rev. Sci. Tech. 2011, 30, 189-206. [CrossRef]

9. OIE/-FAO Foot-and-Mouth Disease Reference Laboratory Network. WRL_FMD_Reports. Annual Report 2015; World Reference Laboratory for FMD: Surrey, UK, 2015. Available online: OIE-FAOFMDRefLabNetworkReport2015.pdf(wrlfmd.org) (accessed on 21 August 2021).

10. Knowles, N.J.; Bachanek-Bankowska, K.; Wadsworth, J.; Mioulet, V.; Valdazo-Gonzalez, B.; Eldaghayes, I.M.; Dayhum, A.S.; Kammon, A.M.; Sharif, M.A.; Waight, S.; et al. Outbreaks of Foot-and-Mouth Disease in Libya and Saudi Arabia During 2013 Due to an Exotic O/ME-SA/Ind-2001 Lineage Virus. Transbound. Emerg. Dis. 2016, 63, e431-e435. [CrossRef]

11. Fishbourne, E.; Ludi, A.B.; Wilsden, G.; Hamblin, P.; Statham, B.; Bin-Tarif, A.; Brocchi, E.; Grazioli, S.; Dekker, A.; Eble, P.; et al. Efficacy of a High Potency O1 Manisa Foot-and-Mouth Disease Vaccine in Cattle against Heterologous Challenge with a Field Virus from the O/ME-SA/Ind-2001 Lineage Collected in North Africa. Vaccine 2017, 35, 2761-2765. [CrossRef]

12. Qui, Y.; Abila, R.; Rodtian, P.; King, D.P.; Knowles, N.J.; Ngo, N.T.; Le, V.T.; Khounsy, S.; Bounma, P.; Lwin, S.; et al. Emergence of Exotic Serotype O Foot-and-Mouth Disease Virus O/ME-SA/Ind-2001d in South-East Asia in 2015. Transbound. Emerg. Dis. 2018, 65, e104-e112.

13. Hicks, H.M.; Wadsworth, J.; Azhar, M.; Afzal, M.; Manzoor, S.; Abubakar, M.; Khan, E.H.; king, D.P.; Knowles, N.J. Genome Sequences of Foot-and-Mouth Disease Virus O/ME-SA/Ind-2001e Strains Isolated in Pakistan. Microbiol. Resour. Announc. 2020, 9, e00165-20. [CrossRef] [PubMed]

14. Jamal, S.M.; Khan, S.; Knowles, N.J.; Wadsworth, J.; Hicks, H.M.; Mioulet, V.; Bin-Tarif, A.; Ludi, A.B.; Shah, S.A.A.; Abubakar, M.; et al. Foot-and-Mouth Disease Viruses of the O/ME-SA/Ind-2001e Sublineage in Pakistan. Transbound. Emerg. Dis. 2021. online ahead of print. [CrossRef] [PubMed]

15. OIE. FMD_Manual. Foot and Mouth Disease (Infection with Foot and Mouth Disease Virus). In OIE Terestrial Manual: Chapter 3.1.8; OIE: Paris, France, 2017.

16. Singanallur, N.B.; Dekker, A.; Eble, P.; Kluitenberg, F.v.; Weerdmeester, K.; Horsington, J.; Vosloo, W. Comparing the Efficacy of Two FMDV Serotype A Emergency Vaccines against Heterologous Challenge with an A/ASIA/G IX/SEA-97 Variant Virus. Vaccines 2020, 8, 80. [CrossRef] [PubMed]

17. Dekker, A.; Sanz-Bernado, B.; Phaedra, E.; King, D.; Singanallur, N.B.; Vosloo, W. Good Quality A Malaysia 97 Protects against A/ASIA/G-VII (A/IRN/22/2015). Vaccines 2020, 8, 24. [CrossRef]

18. Horsington, J.; Perez, C.B.; Maradei, E.; Novo, S.G.; Gonzales, J.L.; Singanallur, N.B.; Bonastre, P.; Vosloo, W. Protective Effects of High-Potency FMDV O1 Manisa Monovalent Vaccine in Cattle Challenged with FMDV O/SKR/2010 at 7 or 4 Days Post Vaccination. Vaccine 2017, 35, 5179-5185. [CrossRef] [PubMed]

19. Vosloo, W.; Nguyen, H.T.T.; Fosgate, G.T.; Morris, J.M.; Wang, J.; Kim, P.V.; Quach, N.V.; Le, P.T.T.; Hung, D.; Tran, H.X.; et al. Efficacy of a High Potency O1 Manisa Monovalent Vaccine against Heterologous Challenge with a FMDV O Mya98 Lineage Virus in Pigs 4 and 7 Days Post Vaccination. Vaccine 2015, 33, 2778-2785.

20. Singanallur, N.B.; Nguyen, H.T.T.; Fosgate, G.T.; Morris, J.M.; Davis, A.; Giles, M.; Kim, P.V.; Quach, N.V.; Le, P.T.T.; Nguyen, P.N.H.; et al. A Malaysia 97 Monovalent Foot-and-Mouth Disease Vaccine ( $>6$ pd50/Dose) Protects Pigs against Challenge with a Variant FMDV A SEA-97 Lineage Virus, 4- and 7- Days Post Vaccination. Vaccine 2015, 33, 4513-4519.

21. Moonen, P.; Jacobs, L.; Crienen, A.; Dekker, A. Detection of Carriers of Foot-and-Mouth Disease Virus among Vaccinated Cattle. Vet. Microbiol. 2004, 103, 151-160. [CrossRef]

22. Golding, S.M.; Hedger, R.S.; Talbot, P. Radial Immuno-Diffusion and Serum Neutralisation Techniques for the Assay of Antibodies to Swine Vesicular Disease. Res. Vet. Sci. 1976, 20, 6. [CrossRef]

23. Bouma, A.; Dekker, A.; de Jong, M.C. No Foot-and-Mouth Disease Virus Transmission between Individually Housed Calves. Vet. Microbiol. 2004, 98, 29-36. [CrossRef]

24. Moonen, P.; Boonstra, J.; van der Honing, R.H.; Leendertse, C.B.; Jacobs, L.; Dekker, A. Validation of a Lightcycler-Based Reverse Transcription Polymerase Chain Reaction for the Detection of Foot-and-Mouth Disease Virus. J. Virol. Methods 2003, 113 , 35-41. [CrossRef]

25. Bates, D.; Maechler, M.; Bolker, B.; Walker, S. Fitting Linear Mixed-Effects Models Using Lme4. J. Stat. Softw. 2015, 67, 48. [CrossRef]

26. R-Core-Team. R: A Language and Environment for Statistical Computing; R Foundation for Statistical Computing: Vienna, Austria, 2019. Available online: https:/ / www.R-Project.Org/ (accessed on 21 August 2021).

27. OIE/FAO Foot-and-Mouth Disease Reference Laboratory Network. WRL_FMD_Reports. Annual Report 2016; World Reference Laboratory for FMD: Surrey, UK, 2016. Available online: OIE-FAOFMDRefLabNetworkReport2016.pdf(wrlfmd.org) (accessed on 21 August 2021).

28. Cox, S.J.; Barnett, P.V.; Dani, P.; Salt, J.S. Emergency Vaccination of Sheep against Foot-and-Mouth Disease: Protection against Disease and Reduction in Contact Transmission. Vaccine 1999, 17, 1858-1868. [CrossRef] 
29. Doel, T.R.; Williams, L.; Barnett, P.V. Emergency Vaccination against Foot-and-Mouth Disease: Rate of Development of Immunity and Its Implications for the Carrier State. Vaccine 1994, 12, 592-600. [CrossRef]

30. Horsington, J.; Zhang, Z.; Bittner, H.; Hole, K.; Singanallur, N.B.; Alexandersen, S.; Vosloo, W. Early Protection in Sheep against Intratypic Heterologous Challenge with Serotype O Foot-and-Mouth Disease Virus Using High-Potency, Emergency Vaccine. Vaccine 2015, 33, 422-429. [CrossRef]

31. Arzt, J.; Juleff, N.; Zhang, Z.; Rodriguez, L.L. The Pathogenesis of Foot-and-Mouth Disease I: Viral Pathways in Cattle. Transbound. Emerg. Dis. 2011, 58, 291-304. [CrossRef]

32. Orsel, K.; de Jong, M.C.; Bouma, A.; Stegeman, J.A.; Dekker, A. The Effect of Vaccination on Foot and Mouth Disease Virus Transmission among Dairy Cows. Vaccine 2007, 25, 327-335. [CrossRef]

33. Sutmoller, P.; McVicar, J.W.; Cottral, G.E. The Epizootiological Importance of Foot-and-Mouth Disease Carriers. I. Experimentally Produced Foot-and-Mouth Disease Carriers in Susceptible and Immune Cattle. Arch Gesamte Virusforsch 1968, 23, 227-235. [CrossRef]

34. Backer, J.A.; Engel, B.; Dekker, A.; van Roermund, H.J.W. Vaccination against Foot-and-Mouth Disease II: Regaining FMD-Free Status. Prev. Vet. Med. 2012, 107, 41-50. [CrossRef]

35. Backer, J.A.; Hagenaars, T.J.; Nodelijk, G.; van Roermund, H.J.W. Vaccination against Foot-and-Mouth Disease I: Epidemiological Consequences. Prev. Vet. Med. 2012, 107, 27-40. [CrossRef]

36. Tenzin, A.D.; Vernooij, H.; Bouma, A.; Stegeman, A. Rate of Foot-and-Mouth Disease Virus Transmission by Carriers Quantified from Experimental Data. Risk Anal. 2008, 28, 303-309. [PubMed]

37. Bertram, R.M.; Vu, L.T.; Pauszek, S.J.; Brito, B.P.; Hartwig, E.J.; Smoliga, G.R.; Hoang, B.H.; Phuong, N.T.; Stenfeldt, C.; Fish, I.H.; et al. Lack of Transmission of Foot-and-Mouth Disease Virus from Persistently Infected Cattle to Naïve Cattle under Field Conditions in Vietnam. Fontiers Vet. Sci. 2018, 5, 174. [CrossRef]

38. Orsel, K.; Roest, H.I.; Elzinga-Bril, E.M.; van Hemert-Kluitenberg, F.; Dekker, A. Detection of Foot-and-Mouth Disease Virus in Infected Pigs by Rt-Pcr Four Weeks after Challenge. Vet. Rec. 2008, 162, 753-754. [CrossRef] [PubMed] 